\title{
Effects of Spiritual Change on the Re-Entry Adjustment of Christian Young Adult Humanitarian Workers
}

\author{
Thomas Wartenweiler \\ University of East London and Lancaster University, UK \\ Francisco Jose Eiroa-Orosa \\ University of East London, UK
}

\begin{abstract}
Humanitarian work inevitably involves exposure to suffering, stress and trauma. Such exposure has a profound effect on an aid worker's worldview and spirituality. The aim of this study was to use Interpretative

Phenomenological Analysis to do an in-depth analysis of how Christian young adult humanitarian workers in faithbased aid organizations experience such spiritual change and how it affects the re-entry into their faith community. Strategies for pastoral and spiritual care for the workers are provided
\end{abstract}

Keywords: Faith-based, humanitarian, IPA, post-traumatic spiritual growth, re-entry, spiritual change 


\section{Effects of Spiritual Change on the Re-Entry Adjustment of Christian Young Adult Humanitarian Workers}

Humanitarian work inevitably involves exposure to suffering, stress and trauma. Increased awareness of how aid workers are affected by post-traumatic stress disorder and vicarious traumatization has led to a call for better training and care within aid organizations in recent years (e.g. Connorton, Perry, Hemenway \& Miller, 2012). With an increased focus on building resilience in humanitarian work, spirituality has emerged as a key factor (Erikson et al., 2009; Peres, Moreira-Almeida, Nasello \& Koenig, 2007; Selby, 2009a) and has received more attention in the humanitarian field. Yet it remains under-researched in regards to the aid worker, as most research on spirituality in the humanitarian sector is geared towards beneficiaries (e.g. Onyango et al., 2011 or Schafer, 2010).

Thus, while the importance of spirituality within humanitarian work has become more evident, workers are still often underprepared for the impact that humanitarian fieldwork has on their worldviews (Blanchetierre, 2006) or their spirituality (Eriksson et al., 2015). McKay (2010) finds that within humanitarian work, "experiencing significant spiritual challenge at some point is almost inevitable" (p. 11) and that "many humanitarian workers, even the nonreligious, experience at least one 'crisis of faith' during their careers" (p. 14). If we therefore assume that spiritual change is a given for most humanitarian workers, be it positive (e.g. post-traumatic spiritual growth, see O’Rourke, Tallman \& Altmaier, 2008; Shaw, Joseph \& Linley, 2005) or negative (e.g. loss of faith, cynicism), an interesting question that arises is how such spiritual change affects the re-entry experience of aid workers. Although cross-cultural adjustment to a new culture is well researched, there is relatively little research on the challenges of returning to one's own culture (re-entry). Szudlarek's (2010) extensive literature review concludes that "the issue of returning home remains largely neglected within the academic community as well as among practitioners managing the cross-border mobility of intercultural sojourners" (p. 2). This is despite good evidence that the re-entry process is often a bigger challenge than the initial cross-cultural adaptation (Sussman, 2000) and is experienced by many similarly to the stages of grief in bereavement (Chamove \& Soeterik, 2006), involving significant loss (Selby et al., 2009b).

The role of spirituality in cross-cultural adjustment has again been researched to a greater degree in the process of entering a new culture (e.g. Lewis Hall, Edwards \& Hall, 2006). Szudlarek (2010) notes that there is very little research looking into the importance of spirituality in the re-entry process despite the fact that "religion can play an important role in the process of dealing with the emotional and psychological aspects of repatriation" (p. 6). There are a few studies looking at spirituality in the context of re-entry, e.g. Kimber's (2012) quantitative research 
on the role of spirituality for the re-entry adjustment of missionaries, and Selby's (2009b; 2011) qualitative work on resilience in re-entering missionaries. However, to our knowledge no qualitative studies investigating humanitarian workers in this context have been published.

This study focused on humanitarian staff workers at Christian faith-based aid organizations. Such workers often enter the field in a faith stage that is characterized by strong beliefs and clear behavioral expectations given by the faith community they belong to, which Fowler (1995) would describe as the synthetic-conventional stage of faith. Piaget's model of assimilation and accommodation, adapted by Block (1982) and Ying (2002) to describe the process of meaning-making in the context of cross-cultural adjustment, is helpful to explain how the humanitarian worker will initially try to assimilate new experiences into his or her existing belief structure, yet may come to a point when this is no longer possible and will be forced to accommodate (change) some of these beliefs. Such changes, be they positive or negative from the aid worker's perspective, potentially have major consequences in regards to belonging and fitting in with their former faith community. The aim of this study was therefore to explore what are Christian humanitarian workers' experiences of spiritual change while in the field, and how do these experiences affect their re-entry adjustment process.

Spirituality is defined broadly for this study as a personal attempt to make meaning and connect with the transcendent or sacred (Peres et al., 2007). While spirituality is a universal human experience and is therefore distinct from religiosity (a set of beliefs upheld by a religious group or institution) (de Meezenbroek et al., 2012), there is much overlap between the two for the participants of this study as they are all embedded in a faith community. In the context of this research, the term spirituality therefore encompasses the concepts of religiosity and faith.

\section{Methods}

A qualitative approach was used in this study because spiritual matters are highly subjective and individual. King and Crowther (2004) argue that due to its fluidity, spirituality cannot be measured well objectively. While quantitative studies such as Eriksson's (2015) longitudinal study show that spiritual changes do take place for humanitarian workers, they don't offer much insight into the nature of those changes. Quantitative instruments such as the Spiritual Transcendence Scale, when used with large sample sizes, allow for greater generalization of results, but provide somewhat abstract concepts about spirituality that don't always help explain in more detail why a worker would experience re-entry struggles due to spiritual change. In contrast, qualitative instruments such as open-ended 
interview questions seem ideal for exploring what triggers spiritual change, how this change is felt, and how humanitarian aid workers process re-acculturation.

The method of Interpretative Phenomenological Analyses (IPA) was chosen to describe and interpret the subjective lived experiences of spiritual change and re-entry of the participants. This method fits the needs of the present project precisely because it does not claim objectivity in interpreting highly subjective processes such as spirituality, but acknowledges both the participants' and the researcher's influence in the double hermeneutic of interpreting the participants' interpretation of their experience (Smith \& Osborn, 2003). An interpretative method was chosen over descriptive qualitative methods, as it seemed important to find out why spiritual change came about and how it unfolded over time (Elliott \& Timulak, 2005). The study's aim was to explore in depth the experiences of three young adults and to discover whether themes with broader relevance may emerge. The small sample size allowed for greater depth in the analysis, and giving adequate weight to the "gems...the relatively rare utterance that is especially resonant and offers potent analytic leverage for the study" (Smith, 2011a, p.6).

\section{Design}

Semi-structured interviews were conducted with three participants. Interviews were then analyzed using Interpretative Phenomenological Analysis (IPA) according to the principles developed by Smith, Jarman and Osborn (1999). Two superordinate themes with various subthemes emerged from the analysis.

\section{Participants}

Purposive sampling was used to create a small, homogenous group of participants who met the following criteria: (a) They had already been on at least one long-term humanitarian assignment (2 years or more) with a Christian faith-based organization; (b) they self-reported major spiritual changes while in the field; (c) they returned from the field at least 6 month prior to the interview. These criteria allowed for both prolonged exposure to humanitarian work and adequate time for processing the re-entry experience. Various faith-based Christian aid organizations were contacted via email in order to identify potential participants for the study. An email explaining the research was then sent to potential participants who had signaled interest. Potential participants were contacted and three who met all the inclusion criteria were chosen. Interview places and times were arranged via email. For the write-up of the research results, a pseudonym was given to each participant to protect their identity: Tracy, a 26year-old Caucasian American woman, married, 2.5 years in the field; Joyce, a 32-year-old multi-racial American woman, single, 3 years in the field; Kevin, a 29-year-old Caucasian American man, single, 4 years in the field. 


\section{Data Collection}

Qualitative data were collected through semi-structured interviews with participants that lasted between 60 and 75 minutes. Each participant gave previous written consent for the study and the recording. One interview took place at a participant's home; the other two were conducted via Skype. The researcher deliberately used open-ended questions, focusing on three main areas: (a) The participant's spirituality while growing up and before cross-cultural assignment; (b) spirituality and spiritual changes while on assignment; (c) the re-entry experience with a special focus on the role of spirituality in the re-entry process.

\section{Data Analysis}

The data were analyzed using IPA (Smith et al., 1999). Each interview was initially transcribed verbatim, read and re-read in order to gain a general perspective of the participant's journey. Each transcript was then annotated by adding comments and observations to the text. Emerging subordinate themes were then identified, connections between them were established, and they were clustered into superordinate themes. This process was repeated for each interview, and finally the most prominent superordinate themes and subordinate themes were chosen for the write-up. Due to the small sample size, only subordinate themes that were present in each account were chosen, according to Smith's (2011b) recommendation. A reflexivity journal based on Landridge's (2007) suggested reflexivity questions was kept to help the researcher in his awareness of personal bias in the process of analysis. By means of investigator triangulation (Biggerstaff, 2012), the emerging themes were discussed (in anonymized form) with member care professionals in the humanitarian sector in order to compare the results with their professional experience.

\section{Results}

While analyzing the data, two super-ordinate themes emerged: the spiritual journey from certainty to mystery and the social journey from belonging to re-orientation.

\section{The Spiritual Journey from Certainty to Mystery}

The participants' narratives all contained descriptions of a journey of gradual spiritual change, which was accelerated by certain catalysts (suffering, cross-cultural encounter, and exposure to other Christian traditions). Subthemes in this change process were identified and labeled as dogmatic certainty at the outset, followed by a period of inner confusion and eventually the emergence of openness to "not-knowing" and embrace of mystery. 
Dogmatic beginnings. All participants reported having grown up in a mainline evangelical or protestant religious environment that endorsed religious dogma and clear social expectations. Faith was a central part of life and was taken seriously.

Tracy: If you are a good Christian, then you will read your bible and have quiet times on a regular basis and pray and kind of have this correct theological understanding... I think a lot of it was very fear-based or guilt-based.... There was very much this fear of God's wrath or punishment.

The participants' narratives pointed to a somewhat paradoxical state during that time. While all participants reflected critically on their religious upbringing, they also recalled a sense of purpose (Joyce: "reaching the unreached"), of being special (Tracy: "this sense of having answers that other people need to know") and of social belonging (Kevin: "my summers were like entirely taken up by church things at that point"; see also second superordinate theme), reflecting the complex and multi-layered experience of growing up in a Christian faith community.

Catalysts of change. While all participants acknowledged that spiritual change was a gradual process that had been happening over years, three distinct catalysts that caused and accelerated this spiritual change emerged from the data: exposure to other Christian faith traditions, cross-cultural encounters, and the experience of suffering.

Exposure to other Christian faith traditions. All three participants reported an initial shifting in their faith during university years, mainly due to leaving their relatively tight-knit social networks and encountering different streams of the Christian faith tradition. While these encounters and processes looked quite different for each participant, there was a clear communality in their engagement with questions about faith and social justice, a fact that would later lead them to go into humanitarian work.

Tracy: [I was] coming to see that there was this social component and justice component to faith, so I think there came a shift in me between seeing the gospel as a set of formulas or beliefs to ascribe to, and shifting more towards, "This is a way of life."

In a similar vein, Joyce recalled that she had become interested in "this idea of community development and recognized that God's Shalom is for us bringing justice and restoration now, not some time in the future." Kevin mentioned at various times how he had struggled with questions of how his faith should be lived out in contemporary society: 
The church I grew up in wasn't particularly good news for the poor... People weren't wrestling with what's our social impact in the world? What would it look like to see justice? How does my lifestyle affect people who are poor?

Cross-cultural exposure. None of the participants seemed to have abandoned any core beliefs before they were immersed into a prolonged cross-cultural setting. Sharing life and building friendships with poor people and with people of other faith traditions brought up a profound wrestling with a worldview that had thus far been taken for granted, leading to doubt and confusion. Tracy recounts an episode in which she was surprised and somewhat unsettled when she was staying with a Muslim family in a slum community and her hosts spoke to her about how they experienced God speaking to them through the Qu'ran.

I remember that being kind of confusing for me because I'm like, “This sounds so similar to my experience with the Bible ..." and I'm kind of trying to make sense of this, like, "What? But you're a Muslim and you're not even praying to Jesus ... what is all this about?"

All three wrestled with questions about salvation. Kevin commented that "some of my thoughts around salvation and atonement have shifted for sure in my time in India, and I think in some helpful ways." Joyce realized that "salvation is bigger than this whole idea of, you know, it's all about just escaping to the clouds one day—but that really salvation is like God's restoration of the cosmos." Tracy illustrated her struggles with the question as follows:

I think the idea of people being condemned basically from the time they were born just because they are not Christians doesn't match up with our own inherent sense of justice ... our consciences basically cry out against this - that people would be born basically as objects of wrath or something. So that really started me thinking about what do I believe in terms of salvation, or how far does the love of God extend? It is like, "Ok, God loves everyone ... who am I to say who is in and who is out?"

Experience of suffering. The biggest effect on the faith journeys of the three participants was due to their experience of suffering. All participants reported much exposure to suffering during their humanitarian assignments, such as: being confronted with poverty, injustice, abuse and trauma. Joyce directly linked the suffering she experienced to theological questions that emerged: "I think you experience so much suffering, and first-hand just see so much pain and loss.... Yeah, the evangelical answers to everything working out all the time don't really work anymore." She later expanded: 
I don't know if it's just evangelicalism, but ... especially in the United States we are taught that we can change the world, you know, and "you can do anything," and it's not really true. I mean, I think just witnessing the vast amount of suffering was just kind of like, "Where are you God? What's the answer to this?"

Kevin experienced the impact of suffering on his faith similarly:

Just hearing some terrible stories and experiencing some of my neighbors' terrible traumas pretty close, I think you naturally ask questions about suffering and where does it come from and why is it here and what is God doing about it and what are we supposed to do about it?

Tracy also started to question God's sovereignty, a belief that is held strongly within evangelical circles:

I really came away from this sense of God's sovereignty in terms of, like, everything that happens is God's will, because I just could not believe that it was God's will to rape and torture each other or for kids to die of diseases that were preventable....I think that's giving God too much credit.

It seems that a confrontation with suffering is inescapable in humanitarian work, and it is an especially powerful catalyst for change because it cuts to the deepest places and has the power to shatter worldviews.

These catalysts of change lead into a liminal space: "a sense of loss or disorientation, losing some solid understanding" (Kevin); "feeling completely unsettled in my faith" (Joyce); "very intense doubt and times of just wondering ... is God there or not, or if God is there, then is God just impotent in this situation?" (Tracy). These feelings were not equally pronounced for each participant. While Kevin seemed to have been least emotionally affected and to have been able to adapt his worldview more gradually, the suffering affected both Joyce and Tracy deeply. Tracy: “At times I would feel totally confused or discouraged or just wondering if the ultimate end of all this would just be having no faith at all, or feeling like there is nothing solid left."

This spiritual disquiet shows how difficult it can be when the ethnocentric evangelical worldview, largely unchallenged while in one's own sub-culture, is being shaken in a cross-cultural context. It is also interesting to see how unsettling and disorienting it is to come to a point where deeply held and cherished beliefs falter under the pressure of difficult experiences.

Embracing mystery and paradox. One of the surprising results of this study is that the participants did not remain in a state of confusion — nor did they abandon their faith. Ultimately their questions lead them to embrace a sense of mystery; of paradox and not-knowing. This is significant because the participants reported 
having been brought up with a strong emphasis on apologetics and on having the "right belief," as Tracy put it. Stepping towards mystery therefore meant leaving behind the clear and reassuring framework of their childhood evangelicalism. Joyce's reflection on the process of allowing herself to not have all the answers is compelling, as we see a new freedom of non-dual thinking emerge through it:

For the first time I let myself feel those questions of, “God, are you good?” And not just like reassuring myself with scriptures or all that stuff, but really letting myself feel that unsettled anxiety. But it felt like grace, because I was able to go into it without answers.

Looking back to her assignment in India, she concluded:

I think I've learned to accept paradox-you know, that things can be good and bad at the same time; that I love India and I hate India at the same time. Yeah, I think I'm embracing paradox. Also, right and wrong matter less to me.

Throughout the interview, Tracy referred to a new found sense of ease with accepting mystery and ambiguity, illustrated in the following statement:

There is a lot we don't know and there is a lot that our theology and spiritual formation has not really prepared us to even ask.... So I would say all those [experiences] led me to more of a sense of mystery; of just recognizing that as much as I might know from my own experiences, there is just always mystery involved. There are a lot of things where we just have to humbly say, "We don't understand this."

Kevin remarked that his theology "sort of exploded in different ways," and then looking back on his cross-cultural experience, concluded that:

I think I have landed in a place that hey, mystery is ok, and that questions are ok; that doubt is good, a ... normal part of the journey of faith. Yeah, and that people ought to be asking questions and ought to be wrestling and that God isn't scared of our questions, God is not scared of our doubts, God is not scared of our anger. I think God is more happy with us to be honest and authentic in the way we are and in what we're struggling with than to sort of tow the party line with, "This is how it works, and this is who's in and who's out."

\section{The Social Journey from Belonging to Re-Orientation}

The participants' narratives display a journey of faith development towards greater inner freedom, a shift that has come through great struggle and personal suffering. For them it has meant leaving behind beliefs that no 
longer work and replacing them with a new set of beliefs that are coherent with their experiences, but which are, at the same time, more ambiguous.

Admitting that they did not have all the answers and that they did not agree with all the answers that their church provided also came at great cost because it meant breaking away from a social group where right beliefs create social cohesion. Similar to the faith journey, there are themes evident in the data that describe a social journey, starting at the point of social belonging within a faith community and progressing through periods of social isolation toward a re-defining of the participants' identity and re-configuration of social networks.

Church as a place of social belonging. Prior to their humanitarian assignments, faith community and church in particular was a central place of belonging for all participants, constituting much of their social network. Tracy spoke of the centrality of church in her life and of how "there was very much a shared culture." She mentioned that all her close friends all the way through college were other Christians. Joyce found that she "kind of had a niche" at youth group, and that within the church there was "definitely a sense of community." Kevin observed that church was "an easy place to receive affirmation" and that "the core of my social time was with other believers." Seeing the integrality of the faith community in participants' lives prior to spiritual change is key in understanding the re-entry experiences.

A sense of disconnect. A key finding of this study is that for a humanitarian worker, spiritual change while in the field will have a major impact on social life during re-entry and post assignment. The participants struggled to different degrees, but the pain in (partially) losing their former place of belonging is evident.

Tracy commented on how difficulties had started while she was still in the field: "It became increasingly difficult to try to communicate my experiences with people back home.... I mean not surprisingly, they weren’t experiencing the same shift in faith." She later spoke of pushback from her church, and said that there were times of "total disconnect." Communicating with her former social network was often frustrating and she felt misunderstood. She generally saw herself as not fitting in anymore with her former church, or with her family and friends, which felt isolating. She concluded:

So I find often now that it seems a lot easier to relate to people who aren't even Christians, or to maybe join into some kind of activism or kind of social initiative with non-believers because at least we can share that kind of vision of justice. And I think sometimes there's more tolerance in those circles for kind of having different beliefs. 
Similarly, Joyce said that upon returning she "didn't feel like [she] fit, really," and that she had therefore become isolated quickly and "didn't really see people at church." She commented that "the hardest part was just losing this identity and then not knowing how to explain to people where I'm at." Kevin's statements resonated with the other two:

There is that sense of disconnect from other people that I maybe once agreed with. Feeling like, wow, a lot of the church really isn't in the place that I'm at, necessarily ... isn't asking these questions, or might be scared by my answers. So then that's a bit isolating or a lonely feeling like, "Yeah, maybe I'm no longer in the in-crowd," or, "I'm a bit different, what do I do with that?"

Another poignant example of his re-entry experience:

I certainly wasn't expecting to be welcomed and understood by most people or most churches, or even by family members or friends who I feel close to, but who haven't necessarily been on the same journey, or don't necessarily share my spirituality and theology.

Censoring self. Not only did all participants find themselves in a place of disconnect from their former faith community - they also felt a need to censor themselves in order to avoid rejection or unnecessary conflict. Tracy said that there were certain topics that she would not talk about with her family because "there is a lot of conflict in terms of my parents feeling quite offended by many of my views, or just feeling offended that I've rejected their kind of worldview in many ways." She spoke of "discerning about to what degree to share" and of "editing a bit" what to share when talking to her former friends about faith matters:

Over time, maybe it seemed that I couldn't be honest with them totally, because, you know, I think there would be misunderstanding and a fear of rejection or a sense of concern that I had left the fold or something.

Joyce contended that "the faith aspect, I don't really share this with very many people." She mused that "maybe I'm just afraid of rejection" and wondered what would happen "if I had been completely transparent, like even now, if I was completely transparent with everyone I'm in relationship with about where I stand on different issues." Kevin's statement sums it up well:

So ideally I'd like to say that I'm being wise, but I think on the flipside, critically I could say yes, sometimes I probably censor myself out of a fear of offense or out of fear of loss of relationship: that sort of things which are not necessarily love but me choosing to censor myself because sometimes you don't want 
to deal with being misunderstood or with being "the weirdo who is always talking about those poor people" sort of thing.

This self-censorship becomes understandable when considering the participants' dogmatic beginnings in their evangelical communities, in which they perceived a culture of black-and-white thinking, with little room for other viewpoints or interpretations of "truth", where someone can easily become socially ostracized or even excommunicated.

A new identity. Similar to the way that their spiritual journeys led to a social re-orientation and an embrace of a new spiritual worldview, the participants' social journeys lead to a newfound identity, andcounterintuitively - to hope. There was a rich tapestry of gratitude in all three accounts when referring to their cross-cultural experiences and spiritual change: "It was a huge gift" (Kevin), "I’m definitely grateful...for what has been formed" (Joyce), "it was really difficult, but positive" (Tracy), "I chose it, and so it was good" (Kevin). A major theme that stood out from the narratives was a new sense of self-worth and purpose that emerged after going through great suffering:

Tracy: At the end of it, I had felt really grateful for all those changes because I feel like there has been a real deepening of my relationship with God. And I think I've gotten beyond a lot of the sense of duty and guilt and fear that had motivated my faith in earlier years, and I feel more a sense of receptivity to God's love and more just a sense of peace in that regard.... It seems like now I can kind of see that this has all been a healthy thing of deconstructing these false selves. It doesn't just leave you with nothing. It can leave you with a truer sense of who you are, and maybe with an identity of God's beloved that's not dependent on what you do or what other people think or having the right actions or right beliefs all the time.

Joyce: I had always kind of deep down thought that God's love for me was dependent on my behavior a little bit, even though cognitively I know that wasn't true. But you know, there was a part of me that kind of thought that God was disappointed in me. But I was in this moment like, "I don't want to be alive anymore" and really sensing God there and knowing that didn't change anything of how I was feeling — but, I don't know, a shift happened in that moment of really knowing, "Well, I'm loved no matter what." 
Kevin: I really felt like — in some ways, for the first time — that I was coming alive in that sense, you know, that the world doesn't need people who are doing good deeds, they need people who have come alive. And it's like, where your deepest passions are, where you come alive and where that meets the world's need, is where you're supposed to be.

All participants reported having found new, supportive, Christian faith communities that allow room for mystery and uncertainty. They also all reported having shifted from being preoccupied with right belief (orthodoxy) to now seeing more value in right action (orthopraxy). Kevin: "I think it's more important that we love people than that our theology is straight." However, despite being grateful for who they have become, there is a keen awareness of the loss of relationship with parts of their former social networks and the pain that has caused.

\section{Discussion}

The interpretative phenomenological analysis of the three interviews has brought to light two distinct yet intertwined processes that the participants underwent: one of spiritual development and one of social re-orientation. Nowadays, it is widely agreed upon that spiritual development is an innate aspect of human development (Friedman, Riebel, Johnson \& Krippner, 2010), progressing in stages similar to cognitive or moral development. Various models of spiritual development exist in academia, as well as in many faith traditions (see Friedman et al., 2010, for a comprehensive review). This study's findings of a progression from certitude through the liminal space of doubt and confusion towards embracing mystery correspond with Fowler's (1995) stages three (synthetic-conventional), four (individuative-reflective), and five (conjunctive), popularized by Peck (1998) as formal-institutional, skepticindividual, and mystic-communal stages. The concept of rites of passage as defined by Van Gennep (1909/2011) is also helpful in interpreting the participants' experience. It consists of (a) a phase of separation from the familiar social structure; (b) a phase of liminality, which is an in-between place of ambiguity outside of clear social structure, or a "state of indeterminacy" (Waaijman, 2006, p.11) that is experienced as disorienting; and (c) a phase of reincorporation into the familiar social environment.

It is therefore not surprising that the participants experienced spiritual change. It is, however, interesting to see how the process was catalyzed not only by exposure to other faith traditions and cultures, but even more so by the experience of suffering. It is also significant that all participants looked back on their experience as "positive," "good" or even "a gift" in the end. While this theme of spiritual growth through suffering has been an integral part of the Perennial Tradition for millennia (Huxley, 1946/2009), it has not appeared in academia until relatively 
recently under the concept of post-traumatic spiritual growth. When reviewing the existing literature, Shaw et al. (2005) point out that while trauma leads to a deepened spirituality for some, this result only occurs for those who demonstrate "positive religious coping, religious openness, readiness to face existential questions, religious participation, and intrinsic religiousness" (p. 1). Other research shows that people who demonstrate negative religious coping may actually experience a loss of faith and increased mental health problems (Altmaier, 2012; O’Rourke et al., 2008; Peres et al. 2007).

While there is an array of quantitative instruments available to measure post-traumatic spiritual growth (see O’Rourke et al., 2008), or spirituality in general (see De Meezenbroek et al., 2012; King \& Crowther, 2004, for reviews), a prominent point of criticism is that spirituality is too subjective and individual to be measured accurately (King \& Crowther, 2004). The personal meaning and depth of spiritual growth can better be captured through interviews and rich concepts such as mystery, grace, or humility, can be explored more deeply through qualitative enquiry.

Much room has been given in this study to exploring the participants' experience of spiritual change, as it is only by understanding the specifics of what this spiritual change looks like that its effect on their re-entry experience can be meaningfully examined. One of the results of this study is that faith-based humanitarian workers who undergo significant spiritual change while in the field struggle with their place of belonging upon returning to their home country. Selby et al. (2011) point out that identity is a significant factor in reentry, and that there is often an "identity gap" between the re-entrant's self-perception and the way the re-entrants is perceived by his or her community. A Christian faith community generally expects members to subscribe to a set of given beliefs in order to belong. The participants' statements clearly describe the development of such an identity gap as their spirituality changes. When considering that "the reentry environment [is] significant in determining sojourner reentry adjustment" (Christofi \& Thompson, 2007, p. 54) and that "those who experience a greater degree of reentry distress also report lower levels of community support" (Kimber, 2012, p. 215), it is not surprising to see how the participants struggled to re-enter into their faith communities. This is in line with Christofi and Thomson's (2007) observation that "the sojourners who adapt well to the host culture experience changes in their values, attitudes, behaviors, ideas, and perceptions and must subsequently integrate these changes with their home culture behavior and attitudes, thus making reentry difficult“ (p. 54). Selby (2009b) found that returning missionary aid workers 
experience "social losses ... either in the community, such as the tangible loss of home community relationships leading to a sense of isolation ... and the intangible loss of understanding by the community” (p. 25).

Not all humanitarian workers struggle to the same degree with spiritual change while in the field. Some worker's spirituality may remain remarkably stable (Eriksson et al., 2015). Other workers may lose their faith completely. The same is true for re-entry. While it is a stressful process for every returner, some workers may feel less isolated and better supported by their faith communities than the participants of this study. What this study demonstrates is that when spiritual change is triggered while away from home (and it often is, under great pressure), it may negatively affect the re-entry experience within the context of a Christian faith community, even when the spiritual change is viewed positively by the humanitarian worker.

\section{Limitations}

This study has some clear limitations. The most important one is sample homogeneity. The small sample size lies within what is appropriate for IPA research design (Smith, 2011b) and allows for portraying the participants' individual journeys by illustrating with rich verbatim extracts within the restraints of academic writing. However, working with three young adult Christian participants in a homogenous sample does not shed light on how humanitarian workers from other faith traditions, from a different age cohort or from other racial backgrounds experience similar re-entry processes. Therefore, similar research with different sample characteristics is recommended. An epistemological limitation lies in the principal researcher's subjectivity and personal bias as an employee of a faith-based humanitarian INGO. While IPA allows for the researcher's active role in interpreting the data (Smith \& Osborn, 2003), the tendency to distort the data was countered by illustrating all interpretations with verbatim extracts, by keeping a reflexivity journal, and by receiving feedback on the emergent themes from member care professionals in the humanitarian sector.

\section{Conclusion}

This study has shown that personal spiritual change is likely to be triggered and accelerated through humanitarian work. It has explored in detail what the process of change can look like for the Christian humanitarian worker. For the participants, spirituality played a central role in their field experience. It has caused confusion and pain and has led to inner liberation and re-shaping of identity. The study's results underline the necessity of continuing the trend among humanitarian organizations of paying increased attention to the workers' spirituality in order to prepare and support them well. 
This is especially important for the re-entry adjustment process. It is a common experience for returning humanitarian workers to initially feel alienated and socially isolated (Canadian Foreign Service Institute, 2009), yet the spiritual dimension of this difficult re-entry process seems to be an under-acknowledged facet of the experience. This is true for the worker (who is often unaware that such spiritual change is likely to happen), for the faith-based aid organization (which often does not adequately prepare the worker for such spiritual changes or for their effects on the re-entry process), and for the faith community (which is often not unwilling, but overwhelmed in reintegrating a worker who has undergone significant spiritual change).

We suggest emotional debriefing as a practical tool for pastoral and spiritual care providers in order to offer re-entry support. Such debriefing is designed to help both the field worker and the sending organizations better understand the worker's experience. It is "an opportunity to hear both the good and the bad without defense (or offense). Its goal should be to discover ways to contribute to support, healing, and preparation for the future" (Pollock, 2002, p. 30). We believe that a listening ear, without judgment, is the most useful support strategy. What seems most unhelpful at this stage is trying to engage the returning field worker in theological debates about correct dogma or right belief. Ideally, a sending church would actively support and encourage the returnee in finding a new and more suitable church community if desired by the worker. We further recommend an assessment of the worker's spiritual health with an instrument such as the Spiritual Health Inventory or similar, and the creation of a self-care plan that may include professional counseling or therapy if necessary. 


\section{References}

Deborah Biggerstaff (2012). Qualitative Research Methods in Psychology, Psychology - Selected Papers, Dr. Gina Rossi (Ed.), ISBN: 978-953-51-0587-9, InTech, doi: 10.5772/38931.

Blanchetière, P. (2006). Resilience of Humanitarian Workers. People in Aid, 8, 17. Retrieved from: http://www.peopleinaid.org/pool/files/publications/resilience-of-aid-workers-article.pdf

Block, J. (1982). Assimilation, accommodation, and the dynamics of personality development. Child Development, 53, 281-295. doi: 10.1111/1467-8624.ep8587768

Centre for Intercultural Learning (2009). Staff reintegration following high-risk missions: Good practices in supporting international development and aid workers. Canadian Foreign Service Institute. Retrieved from: http://www.international.gc.ca

Chamove, A. S., \& Soeterik, S. M. (2006). Grief in returning sojourners. Journal of Social Sciences, 13, $215-220$.

Christofi, V. \& Thompson, C. (2007). You cannot go home again: A phenomenological investigation of returning to the sojourn country after studying abroad. Journal of Counseling \& Development, 85(January 2006), 53-63. doi:10.1002/j.1556-6678.2007.tb00444.x

Connorton, E., Perry, M. J., Hemenway, D., \& Miller, M. (2012). Humanitarian relief workers and trauma-related mental illness. Epidemiologic Reviews, 34, 145-155. doi:10.1093/epirev/mxr026

De Meezenbroek, E. J., Garssen, B., van den Berg, M., van Dierendonck, D., Visser, A., \& Schaufeli, W. B. (2012). Measuring Spirituality as a Universal Human Experience: A Review of Spirituality Questionnaires. Journal of Religion and Health, 51, 336-354. doi:10.1007/s10943-010-9376-1

Elliott, R. \& Timulak, L. (2005). Descriptive and interpretive approaches to qualitative research. In J. Miles \& P. Gilbert (eds.), A Handbook of Research Methods in Clinical and Health Psychology (147-159). Oxford, UK: Oxford University Press.

Eriksson, C. B., Bjorck, J. P., Larson, L. C., Walling, S. M., Trice, G. a., Fawcett, J., ... Foy, D. W. (2009). Social support, organisational support, and religious support in relation to burnout in expatriate humanitarian aid workers. Mental Health, Religion \& Culture, 12(7), 671-686. doi:10.1080/13674670903029146

Eriksson, C. B., Holland, J. M., Currier, J. M., Snider, L. M., Ager, A. K., Kaiser, R. E. R., \& Simon, W. S. (2015). Trajectories of Spiritual Change Among Expatriate Humanitarian Aid Workers: A Prospective Longitudinal Study. Psychology of Religion and Spirituality, 12(1), 13-23. doi:10.1037/a0037703

Fowler, J. W. (1995). Stages of faith: The psychology of human development and the quest for meaning. San Francisco, CA: Harper and Row.

Friedman, H., Riebel, L., Johnson, C., \& Krippner, S. (2010). Transpersonal and Other Models of Spiritual Development. International Journal of Transpersonal Studies, 29(1), 79-94. Retrieved from: http://www.transpersonalstudies.org

Huxley, A. (2009). The perennial philosophy. New York, NY: HarperCollins. (Original work published 1945)

Kimber, T. R. (2012). The Role of Spiritual Development in the Cross-Cultural Reentry Adjustment of Missionaries. Journal of Psychology \& Theology, 40(3), 211-219.

King, J. E., \& Crowther, M. R. (2004). The measurement of religiosity and spirituality: Examples and issues from psychology. Journal of Organizational Change Management, 17, 83-101. doi:10.1108/09534810410511314

Landridge, D. (2007). Phenomenological psychology: Theory, research and method. Essex, UK: Pearson.

Lewis Hall, M. E., Edwards, K. J., \& Hall, T. W. (2006). The role of spiritual and psychological development in the cross-cultural adjustment of missionaries. Mental Health, Religion \& Culture, 9(April), 193-208. doi:10.1080/13694670500355262

McKay, L. (2010). Spirituality and humanitarian work: Maintaining your vitality (Module Six). Headington Institute. Retrieved from: http://www.headington-institute.org

O’Rourke, J. J. F., Tallman, B. a., \& Altmaier, E. M. (2008). Measuring post-traumatic changes in spirituality/religiosity. Mental Health, Religion \& Culture, 11(7), 719-728. doi:10.1080/13674670801993336

Onyango, G. R., Paratharayil, M., van den Berg, S., Reiffers, R., Snider, L., \& Erikson, C. (2011). Spirituality and psychosocial work in emergencies: four commentaries and a response. Intervention, 9(1), 61-73. doi:10.1097/WTF.0b013e3283453ee2

Peck M. S. (1998). The different drum: Community making and peace ( $2^{\text {nd }}$ ed.). New York, NY: Touchstone. 
Peres, J. F. P., Moreira-Almeida, A., Nasello, A. G., \& Koenig, H. G. (2007). Spirituality and resilience in trauma victims. Journal of Religion and Health, 46(3), 343-350. doi:10.1007/s10943-006-9103-0

Pollock, D. (2002). Developing a flow of care and caregivers. In O'Donnell, K., \& O'Donnell, K. S. (Eds.). Doing member care well: Perspectives and practices from around the world. (pp.23-32). Pasadena, CA: William Carey Library.

Schafer, A. (2010). Spirituality and mental health in humanitarian contexts: an exploration based on World Vision's Haiti earthquake response. Intervention, 8(January), 121-130. doi:10.1097/WTF.0b013e32833c1f57

Selby, S., Braunack-Mayer, A., Jones, A., Clark, S., Moulding, N., \& Beilby, J. (2011). Special People? An Exploratory Study into Re-entering Missionaries' Identity and Resilience. Journal of Religion and Health, 50, 1007-1023. doi:10.1007/s10943-010-9337-8

Selby, S., Braunack-Mayer, A., Moulding, N., Jones, A., Clark, S., \& Beilby, J. (2009a). Resilience in re-entering missionaries: why do some do well? Mental Health, Religion \& Culture, 12(7), 701-720. doi:10.1080/13674670903131868

Selby, S., Moulding, N., Clark, S., Jones, A., Braunack-Mayer, A., \& Beilby, J. (2009b). Back home: a qualitative study exploring re-entering cross-cultural missionary aid workers' loss and grief. Omega, 59(1), 19-38. doi:10.2190/OM.59.1.b

Shaw, A., Joseph, S., \& Linley, P. A. (2005). Religion, spirituality, and posttraumatic growth: a systematic review. Mental Health, Religion \& Culture, 8(March), 1-11. doi:10.1080/1367467032000157981

Smith, J. A. (2011a). We could be diving for pearls: The value of the gem in experiential qualitative psychology. Qualitative Methods in Psychology Bulletin, 12, 6-15.

Smith, J. A. (2011b). Evaluating the contribution of interpretative phenomenological analysis. Health Psychology Review, 5(1), 9-27. doi:10.1080/17437199.2010.510659

Smith, J. A. \& Osborn, M. (2003). Interpretive phenomenological analysis. In J.A. Smith (Ed.) Qualitative psychology: A practical guide to research methods (pp.51-80). London: Sage.

Smith, J. A., Jarman, M., \& Osborn, M. (1999). Doing interpretative phenomenological analysis. In M. Murray, K. Chamberlain (Eds.) Qualitative Health Psychology (pp.218-240). Sage.

Sussman, N. M. (2000). The Dynamic Nature of Cultural Identity Throughout Cultural Transitions: Why Home Is Not So Sweet. Personality and Social Psychology Review, 4(4), 355-373. doi:10.1207/S15327957PSPR0404_5

Szkudlarek, B. (2010). Reentry - A review of the literature. International Journal of Intercultural Relations, 34(1), 1-21. doi:10.1016/j.ijintrel.2009.06.006

Van Gennep, A. (2011). The rites of passage. Chicago, IL: University of Chicago Press. (Original work published 1909)

Waaijman, K. (2006). What Is Spirituality? Acta Theologica Supplementum 8, 1-18. doi:10.4314/actat.v27i2.52309

Ying, Y.-W. (2002). The effect of cross-cultural living on personality: assimilation and accommodation among Taiwanese young adults in the United States. The American Journal of Orthopsychiatry, 72(3), 362-371. doi:10.1037/0002-9432.72.3.362 